\title{
Detection of Very Close Targets by Fusion CFAR Detectors
}

\author{
Dejan Ivković ${ }^{1)}$ \\ Milenko Andrićc ${ }^{2)}$ \\ Bojan Zrnićs)
}

\begin{abstract}
In this paper the new application results of Linear and NonLinear Fusion Constant False Alarm Rate (LF-CFAR and NLFCFAR) detectors are presented. Detection of very close targets per azimuth and per range is considered. The entire simulation is done on the basis of the software defined radar receiver. All used CFAR detectors are implemented in mentioned model of the radar receiver. Also, a comparative analysis in detection of very close targets of fusion CFAR detectors versus single CACFAR (Cell Averaging CFAR), OS-CFAR (Ordered Statistic CFAR) and TM-CFAR (Trimmed Mean CFAR) is done. The targets are simulated in a real clutter
\end{abstract}

Key words: detector, detection, target acquisition, radar, software defined radar, clutter.

\section{Introduction}

$\mathrm{D}$ ETECTOR in radar receivers has to be a detector with the adaptive threshold because radars work always in an environment where there are different sources of noise. Therefore, most commonly used detector in radar receivers with this feature is the constant false alarm rate (CFAR) detector. CFAR detectors can be classified according to the applied algorithm into four groups: with algorithms that use the averaging technique, with algorithms that use ordering technique, with algorithms which are the combination of the above mentioned techniques and with algorithms that have some kind of a fusion center in their procedures.

In this paper a detection of very close targets per azimuth and per range using the Linear and NonLinear Fusion Constant False Alarm Rate (LF-CFAR and NLF-CFAR) detectors $[1,2]$ and single CA-CFAR (Cell Averaging CFAR) [3], OS-CFAR (Ordered Statistic CFAR) [4] and TM-CFAR (Trimmed Mean CFAR) is considered [5]. The entire simulation is done on the basis of the software defined radar receiver [6]. The targets are simulated in a real clutter which has been acquired through one real radar device. Acquisition of the real clutter is described in a section about model of the software radar receiver. Here, simulated signal of the target with a given Doppler frequency is superposed to the real acquired signal that represents the real clutter [6].

The paper is organized as follows. The used single and fusion CFAR detectors are described at the beginning briefly. Next, a description of the used model of the software radar receiver is given. Then follow the results of the comparative analysis of detection of very close targets. In the end we gave some conclusions.

\section{Single CFAR detectors}

Single cell averaging, ordered statistic and the trimmed mean CFAR detectors are described in the text below. They reference to a well known CFAR model and many other models are theirs modifications.

\section{A) Cell averaging CFAR detector}

Cell averaging CFAR (Fig. 1) is an optimal CFAR detector when the surveillance zone is homogeneous, when cells of the CFAR detector have contents with the identical clutter distribution.

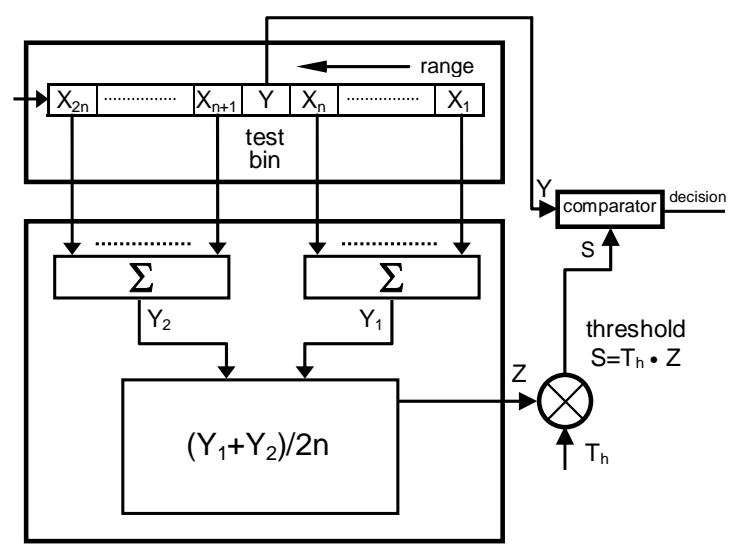

Figure 1. Block diagram of the CA-CFAR detector

The essential parameters of each CFAR are the probability of false alarm rate $P_{f a}$, size of the window detection $N=2 n$, average signal value in cells $Z$, scaling factor of the detection threshold $T$ and detection threshold $S$. Scaling factor of the detection threshold $T$ is a constant which achieves a desired value of the probability of false alarm for a given size of the window detection $N$. The detection window consists of two groups with the same number of cells that are located on the opposite sides with respect to the cell whose contents are tested. CFAR processes signals by averaging of signals in $2 n$

\footnotetext{
1) Military Technical Institute (VTI), Ratka Resanovića 1, 11132 Belgrade, SERBIA

2) University of Defence, Military Academy, Generala Pavla Jurisića Šturma, 33, 11000 Belgrade, SERBIA

3) Serbian Armed Forces, Defence Technologies Department, Nemanjina 15, 11000 Belgrade, SERBIA

Correspondence to: Dejan Ivković; e-mail:dejan.ivkovic@vti.vs.rs
} 
neighbouring range bins $\left(X_{i}\right)$ and the resulting mean value compares with the signal in range bin which is under test $(Y)$. Expression of the probability of detection for CA-CFAR is given as [3]:

$$
P_{D_{C A}}=\left(1+\frac{T}{1+S N R}\right)^{-2 n}
$$

\section{B) Ordered statistic CFAR detector}

Ordered statistic CFAR detector is primarily designed for a situation where in the same moment in a particular area there are several targets whose reflective signals have similar or different amplitudes at the entrance of the detector. Block diagram of OS-CFAR is shown in Fig.2.

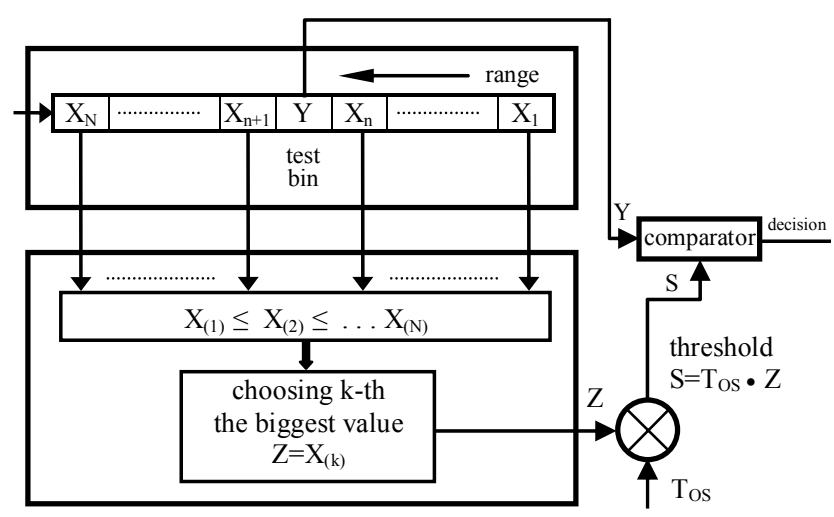

Figure 2. Block diagram of the OS-CFAR detector

In this implementation of CFAR detectors, instead of calculating the mean signal in cells, a cell ordering is done by sorting them in ascending order $X_{(1)}, X_{(2)}, \ldots, X_{(N)}$ of the amplitude. The main idea of the concept of OS-CFAR detector is the selection of a particular value $X_{(k)}$, $k\{1,2, \ldots, N\}$, to obtain the estimated value of an average power of the clutter in the observed window detection. The value of probability of detection for OS-CFAR detector can be calculated by following [4]:

$$
P_{D_{O S}}=k\left(\begin{array}{c}
N \\
k
\end{array}\right) \frac{\Gamma\left(N-k+T_{O S} /(1+S N R)+1\right) \Gamma(k)}{\Gamma\left(N+T_{O S} /(1+S N R)+1\right)}
$$

where $\Gamma$ is gamma function and $T_{O S}$ is scaling factor of the detection threshold.

\section{C) Trimmed mean CFAR detector}

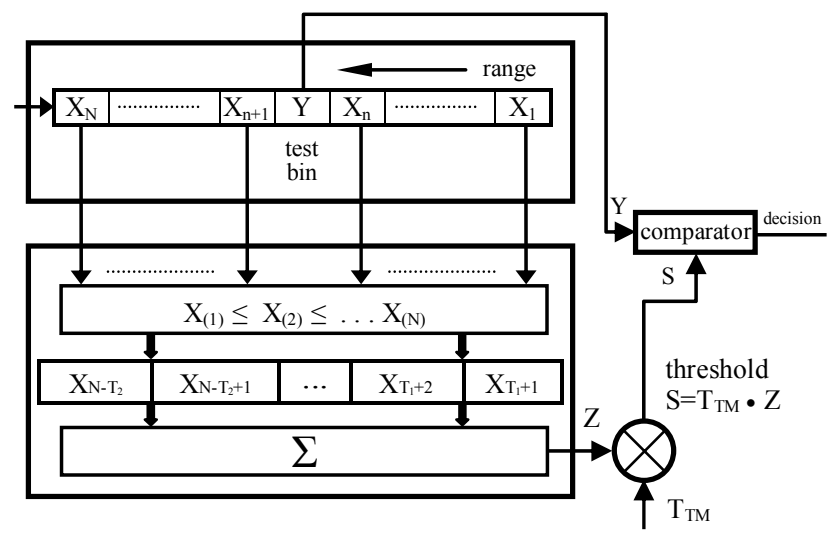

Figure 3. Block diagram of the TM-CFAR detector

Implementation of trimmed mean CFAR detector is a kind of generalization of the original OS-CFAR algorithm in which the clutter power is estimated by a linear combination of the content of sorted cells in the observed window detection. First, we sort cells per amplitude in the window detection, and then discard the $T_{1}$ smallest cells and $T_{2}$ cells with the highest amplitudes. After that, $i$ the summation of the content in the remaining cells is done (Fig.3).

A special case of the TM filter is $\alpha$-TM filter that rejects an equal number of cells $\left(T_{1}=T_{2}\right)$ with minimum and maximum amplitudes. The value of probability of detection for TM-CFAR detector can be calculated by the following equations [5]:

$$
P_{D_{T M}}=\prod_{i=1}^{N-T_{1}-T_{2}} M_{D V_{i}}\left(T_{T M}\right)
$$

$$
\begin{gathered}
M_{D V_{1}}\left(T_{T M}\right)=\frac{N !}{T_{1} !\left(N-T_{1}-1\right) !\left(N-T_{1}-T_{2}\right)} . \\
\sum_{j=0}^{T_{1}} \frac{\left(\begin{array}{c}
T_{1} \\
j
\end{array}\right)(-1)^{T_{1}-j}}{\frac{N-j}{N-T_{1}-T_{2}}+\frac{T_{T M}}{1+S N R}} \\
M_{D V_{i}}\left(T_{T M}\right)=\frac{a_{i}}{a_{i}+T_{T M} /(1+S N R)} \\
a_{i}=\frac{N-T_{1}-i+1}{N-T_{1}-T_{2}-i+1}, \quad i=2, \ldots, N-T_{1}-T_{2}
\end{gathered}
$$

\section{Fusion CFAR detectors}

Fusion of particular decisions of the single CFAR detectors by appropriate fusion rules provides a better final decision (detection) [8]. Linear and nonlinear fusion CFAR detectors are described in the text below.

\section{A) Linear fusion CFAR detector}

Approach of the linear fusion CFAR detector is based on the parallel operation of three well-known types of CFAR detectors: CA-CFAR, TM-CFAR and OS-CFAR. Simple block diagram of the LF-CFAR detector is shown in Fig.4. In Fig.4 three branches can be seen. In every branch there is one type of CFAR detector (CA, TM or OS), which, depending on the required probability of false alarm rate, the power of the clutter and signal value in the test cell, make a decision about the presence of the reflected signal from the target in the test cell.

These three decisions arrive at the fusion center simultaneously, where a final decision about the presence of the target in the test cell is made. The algorithm takes the final decision by the appropriate fusion rules and potential outputs of the LF-CFAR detector are given in Table 1 (a value of 1 represents the presence of the target, a value of 0 represents no target). The output of the CA-CFAR detector is taken as a reference for the fusion center because it assures high probability of detection. However, sometimes when CACFAR output is 1 , there is a possibility for a false alarm caused by multiple targets or change of the clutter features. To eliminate this false alarm we apply "and" logic between CACFAR output and the outputs obtained by applying the "or" logic between TM-CFAR and SO-CFAR.

Also, there is a real possibility that the target is present but that CA-CFAR output becomes 0 because of strong clutter interference or multiple neighbourhood targets. We apply "and" logic between TM-CFAR and OS-CFAR detectors to eliminate the target lost. 


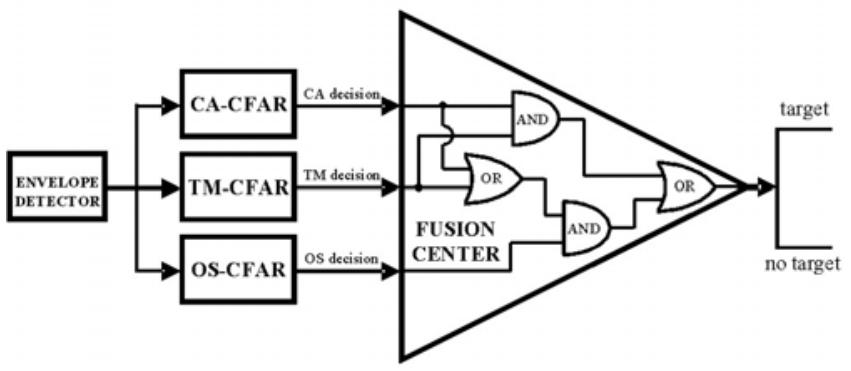

Figure 4. Block diagram of the LF-CFAR detector

Table 1. Possible fusion CFAR outputs

\begin{tabular}{|c|c|c|c||}
\hline \hline CA-CFAR & TM-CFAR & OS-CFAR & Fusion CFAR \\
\hline \hline 0 & 0 & 0 & 0 \\
\hline 0 & 0 & 1 & 0 \\
\hline 0 & 1 & 0 & 0 \\
\hline 0 & 1 & 1 & 1 \\
\hline 1 & 0 & 0 & 0 \\
\hline 1 & 0 & 1 & 1 \\
\hline 1 & 1 & 0 & 1 \\
\hline 1 & 1 & 1 & 1 \\
\hline
\end{tabular}

Events when we have target detection (rows 4, 6, 7 and 8 in Table 1) are mutually exclusive since the occurrence of one of them excludes the occurrence of the other. We know that CA, TM and OS-CFAR decisions are independent events also. Probability of detection $P_{d_{L F}}$ [1] for the proposed fusion CFAR can be calculated according to [9]:

$$
P_{d_{L F}}=P_{d_{T M}} P_{d_{O S}}+P_{d_{C A}}\left(P_{d_{T M}}+2 P_{d_{T M}} P_{d_{O S}}+P_{d_{O S}}\right)
$$

where $P_{d_{C A}}, P_{d_{T M}}$ and $P_{d_{O S}}$ are the probabilities of detection for CA, TM and OS-CFAR, respectively.

\section{B) Nonlinear fusion CFAR detector}

Nonlinear fusion (NLF) CFAR detector [2] is some kind of a modification of LF-CFAR detector. Approach of the NLFCFAR detector is based again on the parallel operation of the same three types of CFAR detectors. But, in this case, the probability of false alarm rate $P_{f a}$ has not the same value in each single CFAR algorithm, as it was in the realization of linear fusion CFAR detector before. The aim of NLF-CFAR is elimination of the largest possible number of false targets with the least possible disruption of the probability of detection of real radar targets. Block diagram of the NLFCFAR detector is shown in Fig.5.

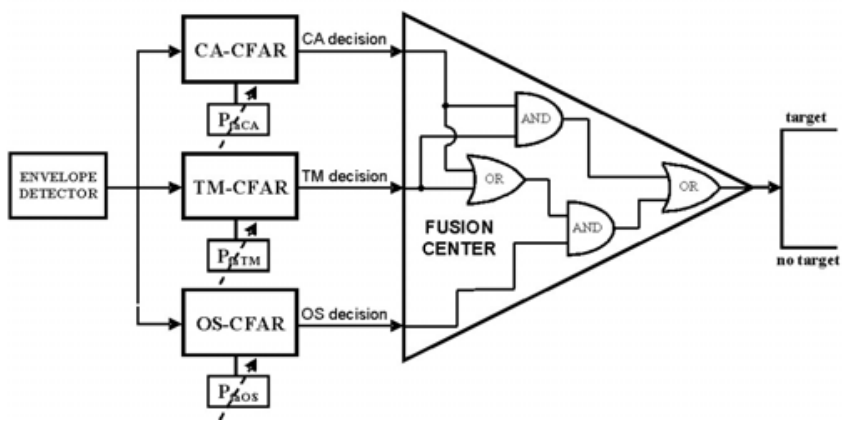

Figure 5. Block diagram of the NLF-CFAR detector

In Fig. 5 three branches can also be seen. Here, the algorithm for making the final decision has the same logical rules for fusion of individual decisions of CFAR detectors as previous LF-CFAR. Potential output data of the NLF-CFAR detector are also shown in Table 1. Based on these facts and decision rules shown in Table 1, the probability of detection of NLF-CFAR detector can be calculated using the equations:

$$
P_{d_{N L F}}=P_{d_{T M}} P_{d_{O S}}+P_{d_{C A}}\left(P_{d_{T M}}+2 P_{d_{T M}} P_{d_{O S}}+P_{d_{O S}}\right)
$$

where again $P_{d_{C A}}, P_{d_{T M}}$ and $P_{d_{O S}}$ are the probabilities of detection for CA, TM and OS-CFAR, respectively.

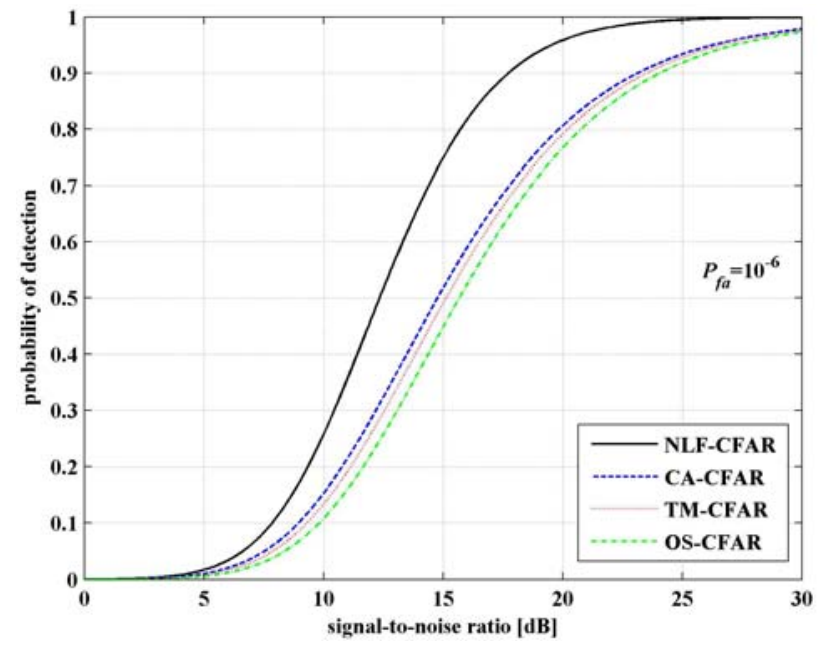

Figure 6. Detection curves of the NLF, CA, TM and OS-CFAR detectors

Probabilities of detection of NLF, CA, TM and OS-CFAR detectors as a function of the signal-to-noise ratio for $P_{f a}=10^{-6}$ and $N=16$ are shown in Fig.6. A significant improve of the probability of detection of the NLF-CFAR detector over the individual CFAR detectors can be noticed. With the increase of the signal-to-noise ratio this effect becomes more pronounced. It can be seen that detection curve of NLF-CFAR detector is approximately $4 \mathrm{~dB}$ above the detection curves of individual CFAR detector for $P_{d}=0.5$.

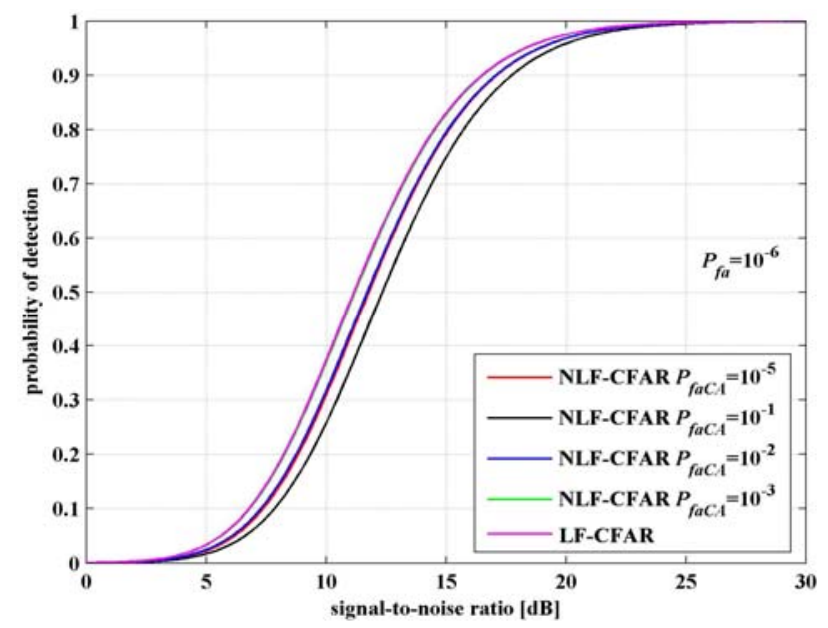

Figure 7. Detection curves of the LF and NLF-CFAR detectors

The desired value of the probability of false alarm rate for NLF-CFAR detector $P_{f a D E S}$ [2] can be obtained by solving the following equation per $P_{f a}^{\prime}$ :

$$
\left(1+2 P_{f a C A}\right) P_{f a}^{\prime 2}+2 P_{f a C A} P_{f a}^{\prime}-P_{f a D E S}=0
$$

where $P_{f a}^{\prime}$ is a needed value of the probability of false alarm rate of individual TM and OS-CFAR detectors and $P_{f a C A}$ is a chosen value of the probability of false alarm rate of individual CA-CFAR detector within NLF-CFAR. Therefore, 
in this realization, on the basis of the chosen and desired probability of false alarm rates of CA and NLF-CFAR detectors respectively, probability of the false alarm rate of individual TM and OS-CFAR detectors is determined. Probabilities of detection of LF and NLF-CFAR detectors for different values of $P_{f a C A}$ as a function of the signal-to-noise ratio for $P_{f a}=10^{-6}$ and $N=16$ are shown in Fig. 7 .

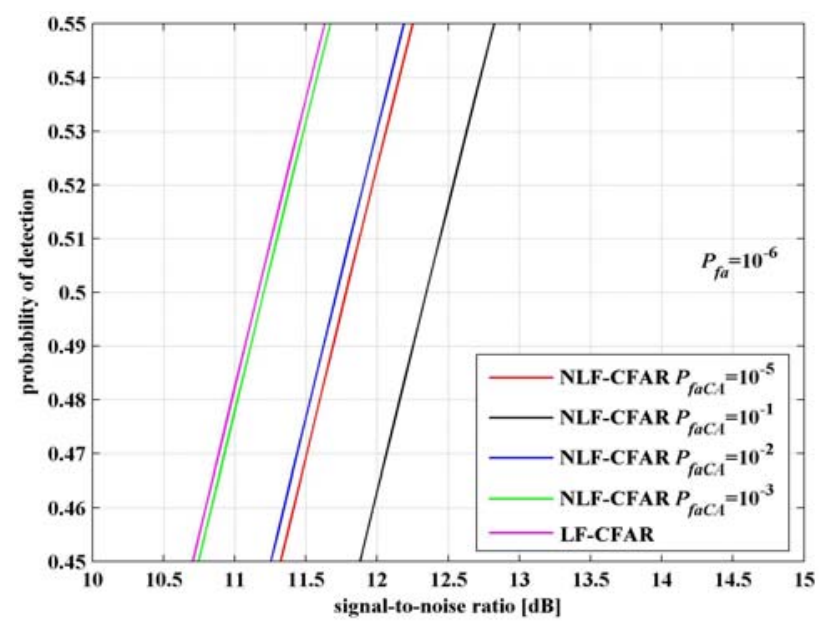

Figure 8. Zoomed detection curves of the LF and NLF-CFAR detectors

It can be seen that LF-CFAR has the best characteristics in terms of probability of detection compared to the considered NLF-CFAR models. This fact is more visible in Fig.8, where it is shown that the losses in the signal to noise ratio of the NLF relative to LF-CFAR algorithm are in the range from $0.04 \mathrm{~dB}$ to $1.18 \mathrm{~dB}$.

\section{Used model of the software radar receiver}

We made a check of the LF, NLF, CA, OS and TM-CFAR by detection of multiple very close simulated targets in a real clutter. The check was performed on the model of software radar receiver (SRR) presented in detail in [6]. Block diagram of the used SRR is shown in Fig.9. Real clutter has been acquired through analog-to-digital (A/D) conversion of signals from I and Q branches of one real radar device. Sampling frequency was $2 \mathrm{MHz}$. Transmitted pulse power of the radar device was $15 \mathrm{KW}$, frequency was $5.4 \mathrm{GHz}$, pulse repetition frequency was $2350 \mathrm{~Hz}$, intermitted frequency was $30 \mathrm{MHz}$, antenna scan rate was $1 \mathrm{~Hz}$ and horizontal antenna beamwidth was $2.1^{\circ}$. Pulse width was $6 \mu$ s and, because of that, the size of resolution cell per range is $900 \mathrm{~m}$.

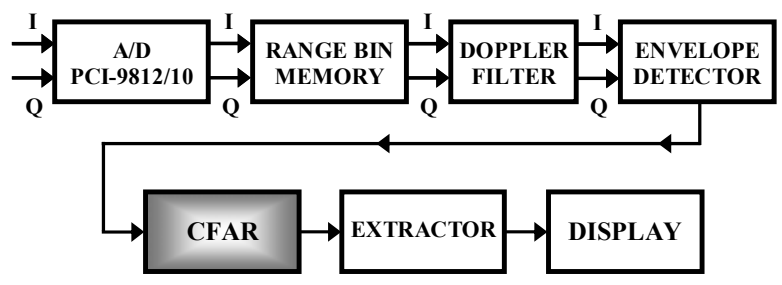

Figure 9. Block diagram of the used SRR

\section{Comparative analysis of the detection of very close targets}

Comparative analysis of the LF, NLF, CA, OS and TMCFAR detectors is realized by interpreting the results of detection of very close targets. We prepared three very difficult scenarios for detection:
- Scenario 1 - a group of four targets on the same azimuth where the distance between two adjacent targets is four radar resolution cells,

- Scenario 2 - a group of four targets on the same azimuth where the distance between two adjacent targets is one radar resolution cell,

- Scenario 3 - a group of ten targets at close distances by range and azimuth.

All targets are simulated in a real clutter. Used CFAR detectors have the same parameters in each scenario. Main parameters of realized CFAR detectors are listed in Table 2, where $P_{f a}$ is the probability of false alarm rate, $N$ is reference window size, $T$ is scaling factor of the detection threshold, $k$ is well known parameter of OS-CFAR algorithm [4] and $T_{1}$ and $T_{2}$ are number of smallest and greatest ranked cells respectively, which are discarded in TM-CFAR algorithm [5].

Table 2. Main parameters of realized CFAR detectors

\begin{tabular}{|c|c|c|c|c|c|c|c|c|}
\hline \multicolumn{2}{|c|}{ "model } & \multicolumn{2}{|r|}{$\overline{P P_{f a}}$} & $\bar{N} N$ & $\bar{T}$ & $\bar{~} \bar{k}$ & $\overline{T T_{1}}$ & $\overline{\bar{T} T_{2}}$ \\
\hline \multirow{3}{*}{$\mathrm{LF}$} & $\overline{\mathrm{CA}}$ & \multirow{6}{*}{$10^{-6}$} & $5.8 \cdot 10^{-4}$ & \multirow{9}{*}{16} & 0.59 & - & - & - \\
\hline & TM & & $5.8 \cdot 10^{-4}$ & & 0.99 & - & 2 & 2 \\
\hline & OS & & $5.8 \cdot 10^{-4}$ & & 8.23 & 12 & - & - \\
\hline \multirow{3}{*}{ NLF } & $\mathrm{CA}$ & & $1.0 \cdot 10^{-4}$ & & 0.78 & - & - & - \\
\hline & TM & & $0.9 \cdot 10^{-3}$ & & 0.91 & - & 2 & 2 \\
\hline & OS & & $0.9 \cdot 10^{-3}$ & & 7.57 & 12 & - & - \\
\hline \multicolumn{2}{|c|}{$\widehat{\mathrm{CA}}$} & \multirow{3}{*}{\multicolumn{2}{|c|}{$10^{-6}$}} & & 1.37 & - & - & - \\
\hline \multicolumn{2}{|c|}{ TM } & & & & 2.38 & - & 2 & 2 \\
\hline \multicolumn{2}{|c|}{$\mathrm{OS}$} & & & & 20.9 & 12 & - & - \\
\hline
\end{tabular}

\section{A) Scenario 1 detection results}

Detection of the group of four targets on the same azimuth where the distance between two adjacent targets is 4 radar resolution cells is considered here. Parameters of the simulated targets are shown in Table 3. Targets have different signal-to-noise ratio $(S N R)$, Doppler frequency and the same azimuth.

Table 3. Scenario 1 - Parameters of simulated radar targets

\begin{tabular}{|c|c|c|c|c|}
\hline \hline Target & SNR $[\mathrm{dB}]$ & $\mathrm{fd}[\mathrm{Hz}]$ & $\mathrm{R}[\mathrm{km}]$ & $\theta\left[{ }^{\circ}\right]$ \\
\hline \hline 1 & 5.2 & 2000 & 4.5 & \multirow{2}{*}{186.1} \\
\cline { 1 - 4 } 2 & 13.1 & 2500 & 9.0 & \\
\cline { 1 - 4 } 3 & 6.9 & 3000 & 13.5 & \\
\hline 4 & 10.7 & 3500 & 18.0 & \\
\hline
\end{tabular}

Free space between the front and the back edge of the two adjacent targets is $3.6 \mathrm{~km}$, which corresponds to the size of the 4 resolution cells, since in our experiment we used an older radar device with a simple pulse modulated sinusoid waveform. This simulated situation is difficult for detection, because we used CFAR detectors with $\mathrm{N}=16$ and then reflected signals from three targets are in reference window simultaneously. These three close targets interfere with each other and produce some kind of jamming. Raw video signal on the output of the envelope detector is shown in Fig.10. Targets are superposed in a real clutter and they cannot be observed simply. Outputs of considered CFAR detectors are shown in Fig.11 to Fig.15.

We can see in Fig.11 that CA-CFAR detects all four targets, but we have many false targets in the nearness. TMCFAR detects only target 4 in this scenario (see Fig.12), but there are no false targets. OS-CFAR detects target 4 and in addition target 1 , also without any false targets. It can be seen in Fig.13. LF and NLF-CFAR detects all four targets (see Figures 14 and 15) but one weak false target appears close to simulated targets 1 and 2 . It is not so bad in this difficult situation, because no single CFAR algorithm could detect all targets. 


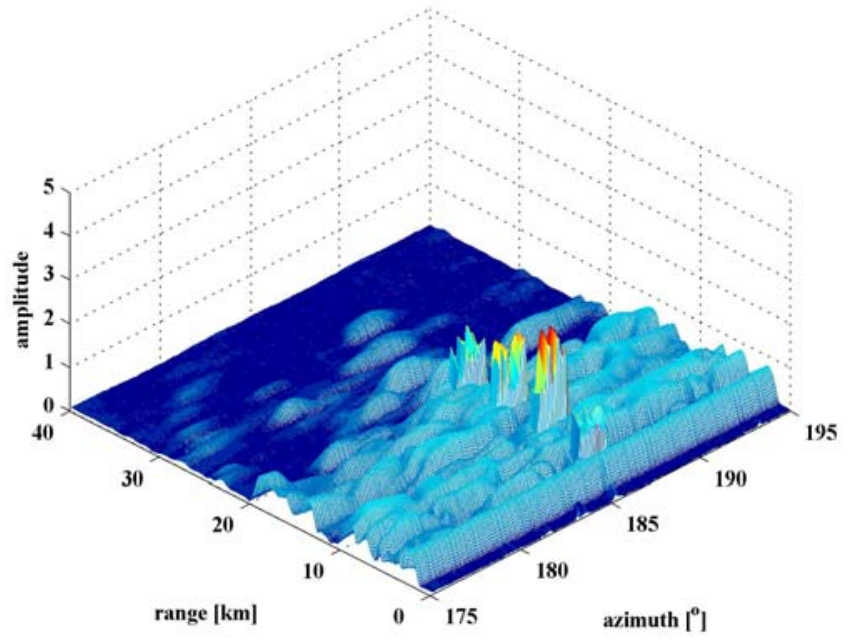

Figure 10. Raw video signal

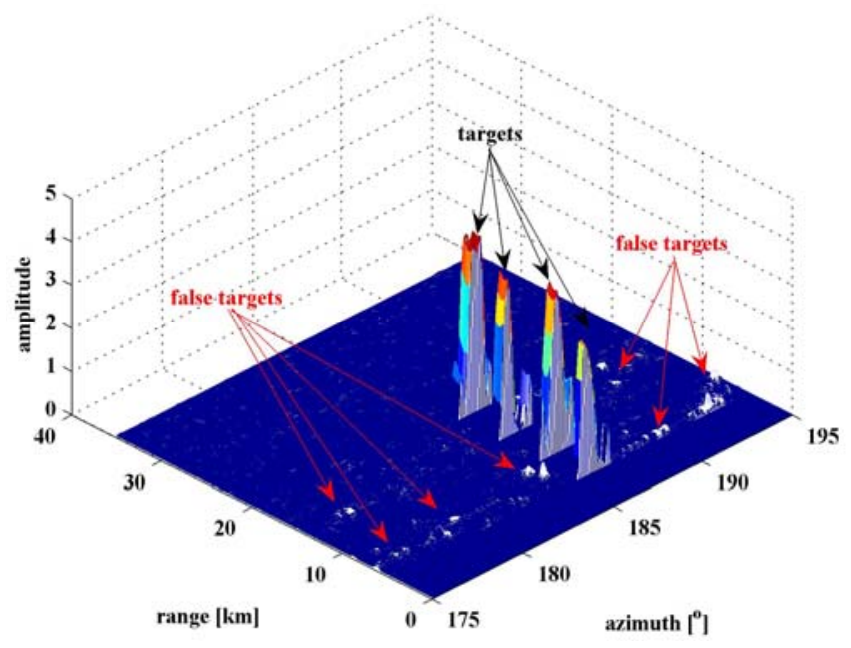

Figure 11. Result of CA-CFAR processing

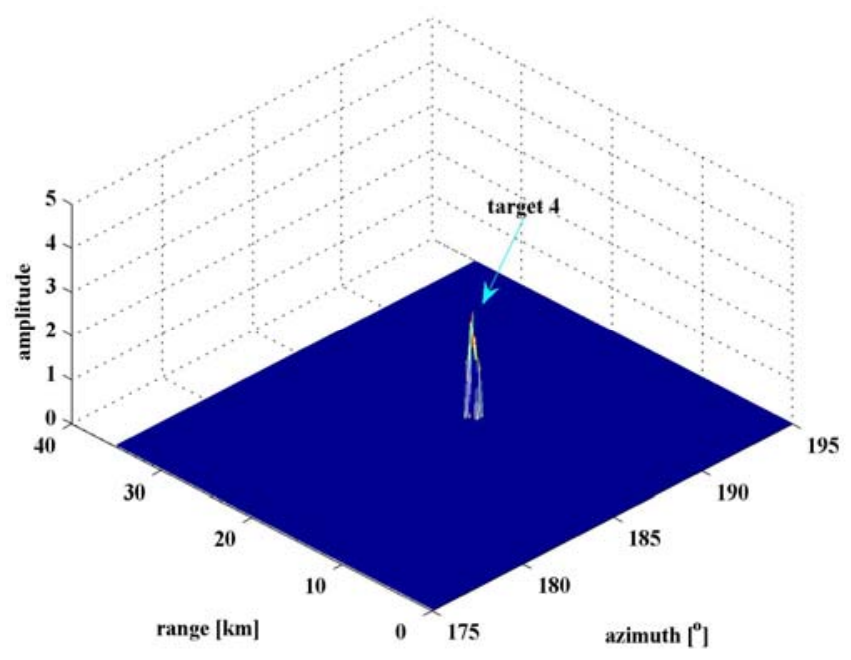

Figure 12. Result of TM-CFAR processing

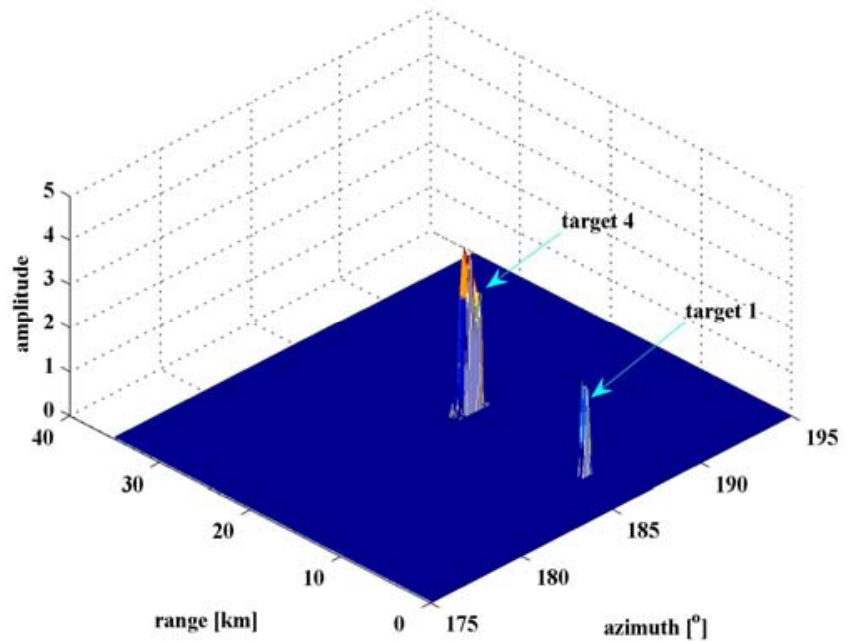

Figure 13. Result of OS-CFAR processing

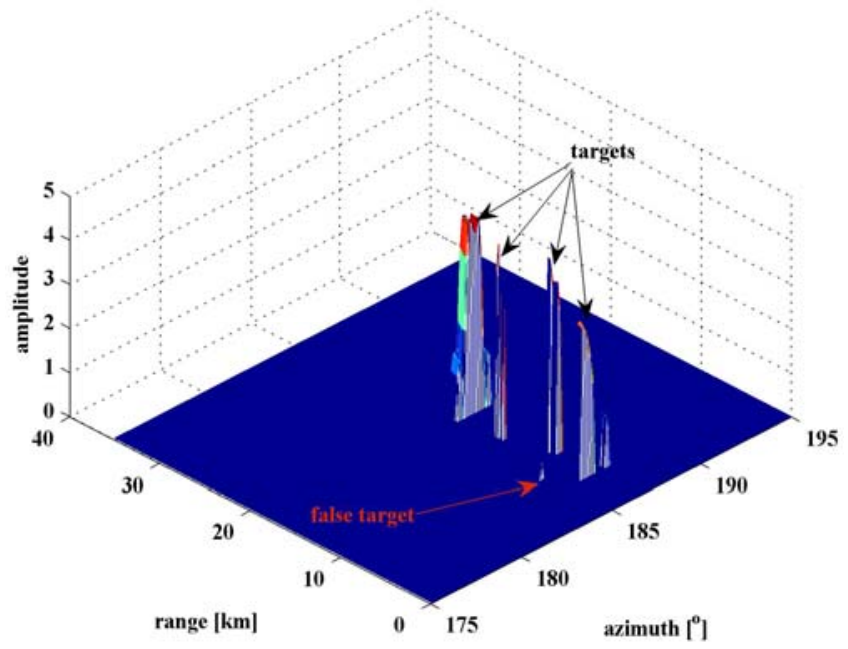

Figure 14. Result of LF-CFAR processing

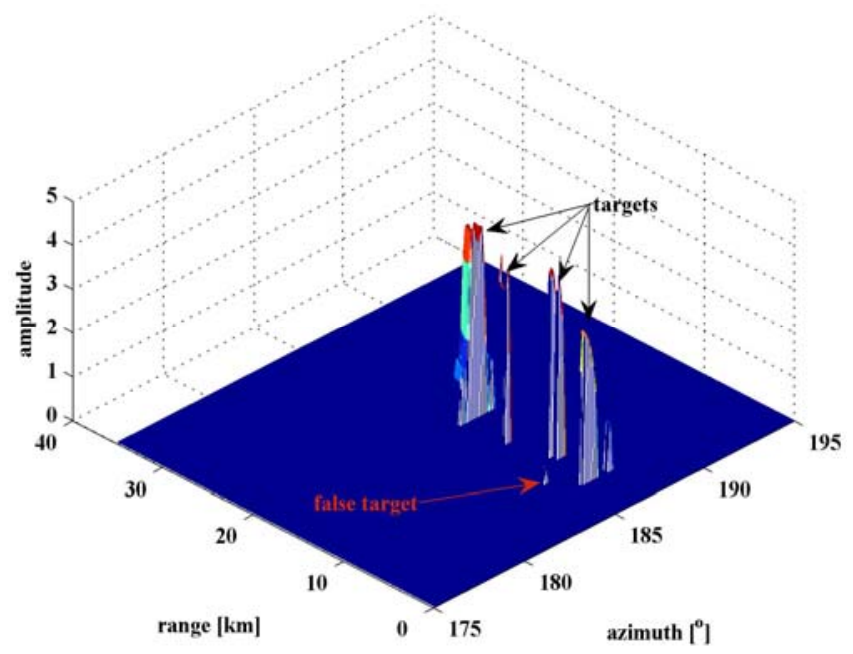

Figure 15. Result of NLF-CFAR processing 


\section{B) Scenario 2 detection results}

Detection of the group of four targets on the same azimuth where the distance between two adjacent targets is only 1 radar resolution cell is considered in this section. Parameters of the simulated targets are shown in Table 4. Reflected signals from targets have same amplitudes and same Doppler frequencies as in scenario 1. SNR are here different because different target positions and different clutter impact in these positions.

Table 4. Scenario 2 - Parameters of simulated radar targets

\begin{tabular}{|c|c|c|c|c||}
\hline Target & SNR [dB] & $\mathrm{fd} \mathrm{[Hz]}$ & $\mathrm{R}[\mathrm{km}]$ & $\theta\left[^{\circ}\right]$ \\
\hline \hline 1 & 6.0 & 2000 & 4.5 & \multirow{2}{*}{186.1} \\
\hline 2 & 10.3 & 2500 & 6.3 & \\
\hline 3 & 8.0 & 3000 & 8.1 & \\
\hline 4 & 8.1 & 3500 & 9.9 & \\
\hline
\end{tabular}

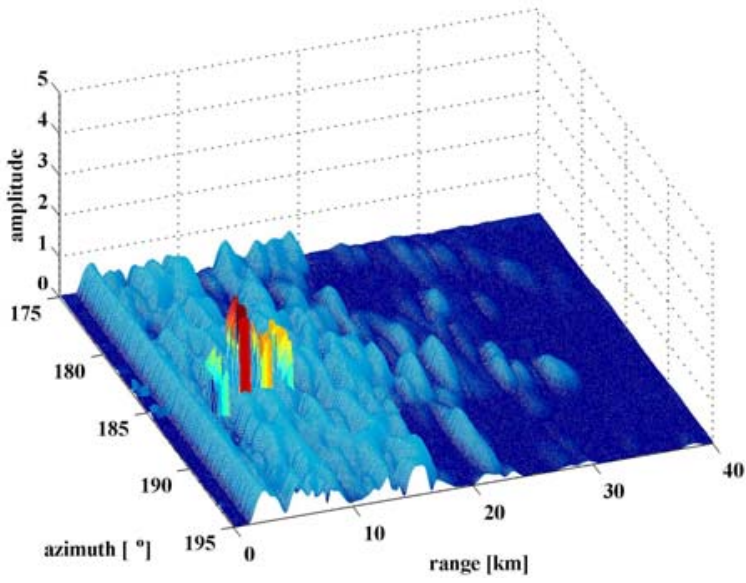

Figure 16. Raw video signal

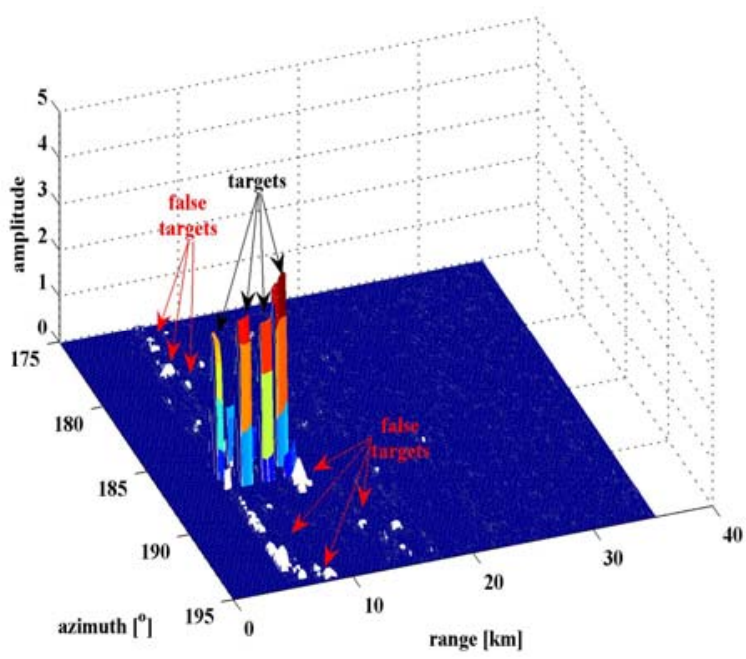

Figure 17. Result of CA-CFAR processing

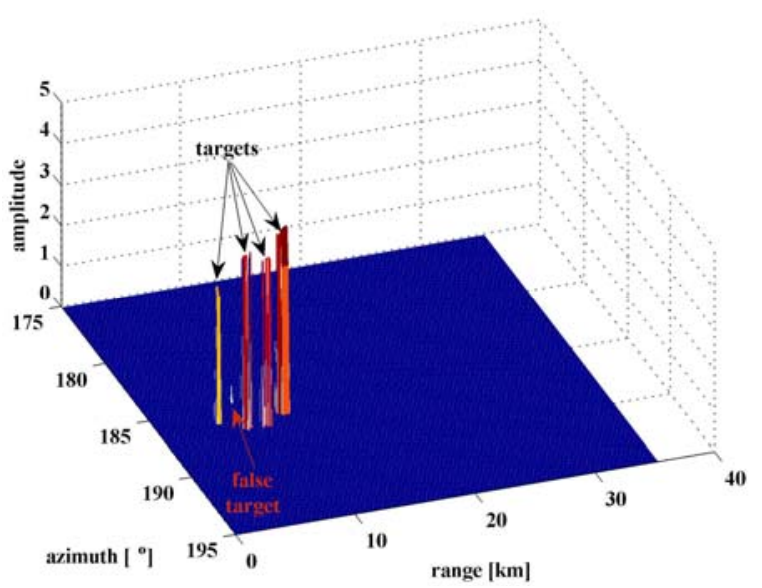

Figure 18. Result of LF-CFAR processing

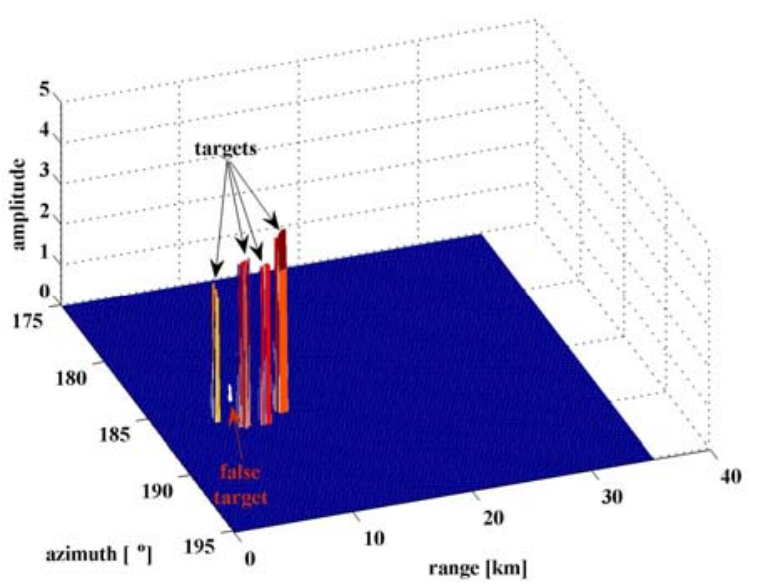

Figure 19. Result of NLF-CFAR processing

Free space between the front and the back edge of the two adjacent targets is $900 \mathrm{~m}$, which, for this radar type, corresponds to the size of only 1 resolution cell. This simulated situation is very difficult for detection, because in reference window with size $N=16$ there are signals from all four targets simultaneously, when reflected signal of any of the four simulated targets is in the test cell. Mutual interference of the targets in this scenario is very strong, so the detectors have a very heavy task. Raw video signal on the output of envelope detector is shown in Fig.16. Outputs of considered CFAR detectors are shown in Fig. 17 to Fig.21. We can see in Fig. 17 that CA-CFAR detects all four targets again, but there are a lot of false targets. TM and OS-CFAR do not detect any. LF and NLF-CFAR detect again all four targets (see Figures 18 and 19) and only one weak false target appears close to simulated targets 1 and 2 .

In this situation all the benefits of the fusion process become recognizable.

\section{C) Scenario 3 detection results}

In this section we consider detection of the group of ten targets at close distances by range and azimuth. Parameters of the simulated targets are shown in Table 5. Targets have different $S N R$, Doppler frequency and azimuth.

Table 5. Scenario 3 - Parameters of simulated radar targets

\begin{tabular}{|c|c|c|c|c||}
\hline Target & $S N R[\mathrm{~dB}]$ & $f_{d}[\mathrm{~Hz}]$ & $R[\mathrm{~km}]$ & $\theta\left[^{\circ}\right]$ \\
\hline \hline 1 & 9.3 & 3000 & 4.5 & 179.6 \\
\hline 2 & 8.0 & 2500 & 6.3 & 181.7 \\
\hline 3 & 7.2 & 3500 & 5.2 & 184.1 \\
\hline 4 & 8.8 & 2000 & 8.1 & 180.5 \\
\hline 5 & 9.3 & 3500 & 7.1 & 184.9 \\
\hline 6 & 13.0 & 2500 & 7.9 & 182.8 \\
\hline 7 & 8.7 & 2000 & 9.9 & 181.2 \\
\hline 8 & 6.5 & 2500 & 9.7 & 183.6 \\
\hline 9 & 6.8 & 3000 & 11.7 & 182.1 \\
\hline 10 & 9.2 & 3000 & 11.5 & 184.5 \\
\hline
\end{tabular}

Radiograms in a horizontal plane are shown in Figures in this section for a better transparency. Places, where targets should be located are marked with rectangles with an appropriate target number. Mutual interference of the targets in this scenario is also very strong. Raw video signal on the output of the envelope detector is shown in Fig.20. Targets are superposed in a real clutter and they cannot be observed simply without the rectangles. Outputs of considered CFAR detectors are shown in Fig.21 to Fig.25. 


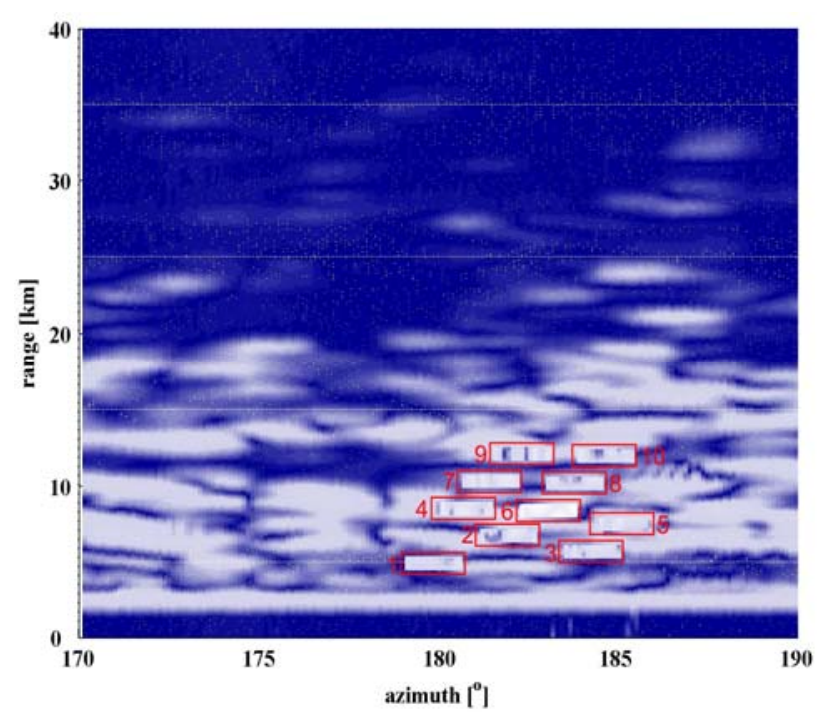

Figure 20. Raw video signal

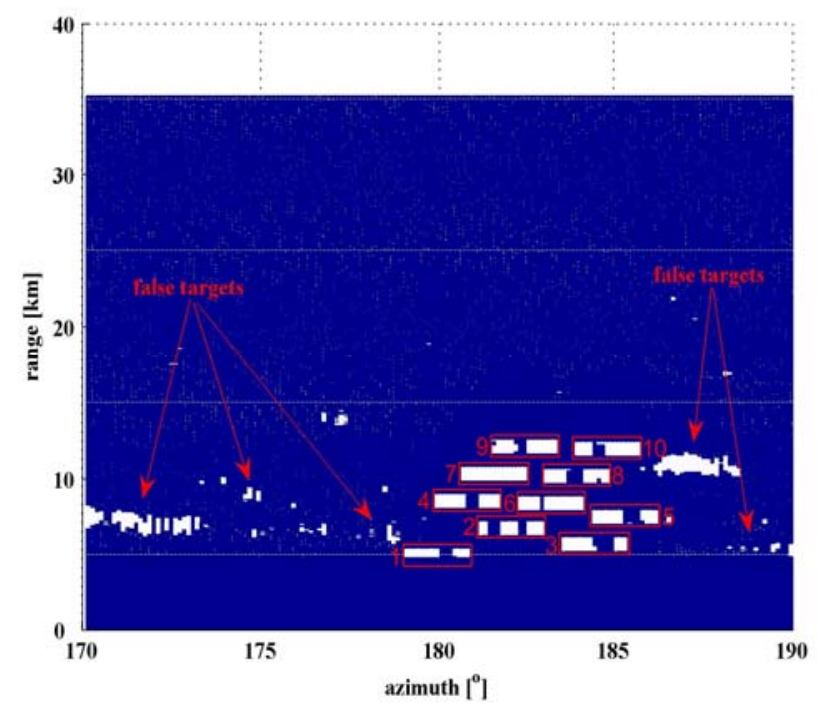

Figure 21. Result of CA-CFAR processing

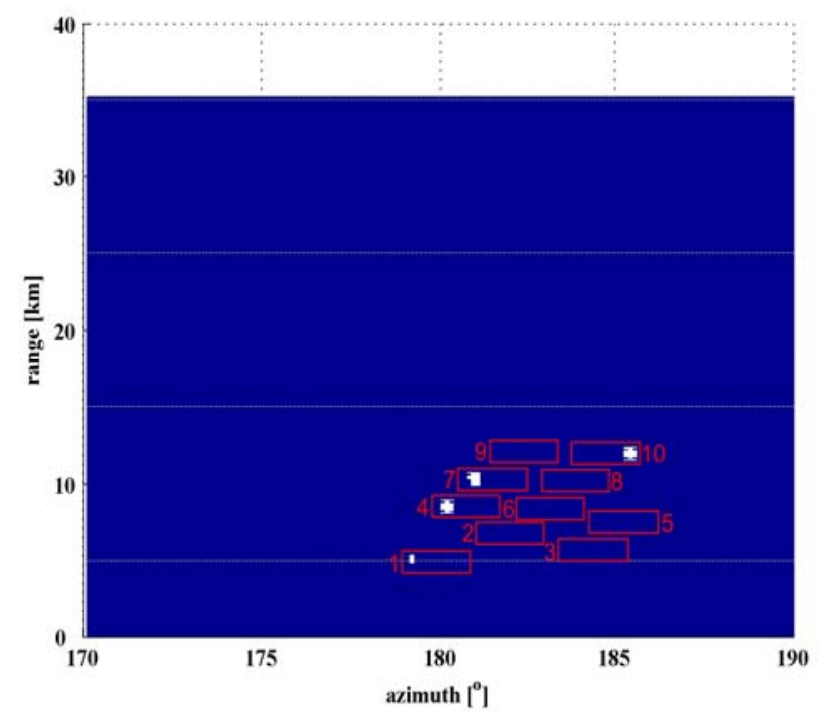

Figure 22. Result of TM-CFAR processing

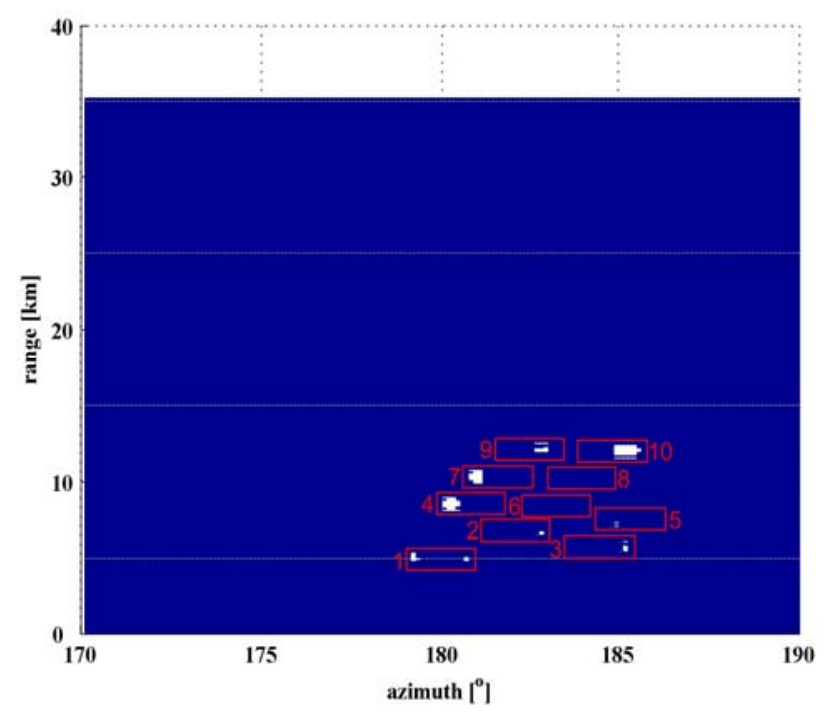

Figure 23. Result of OS-CFAR processing

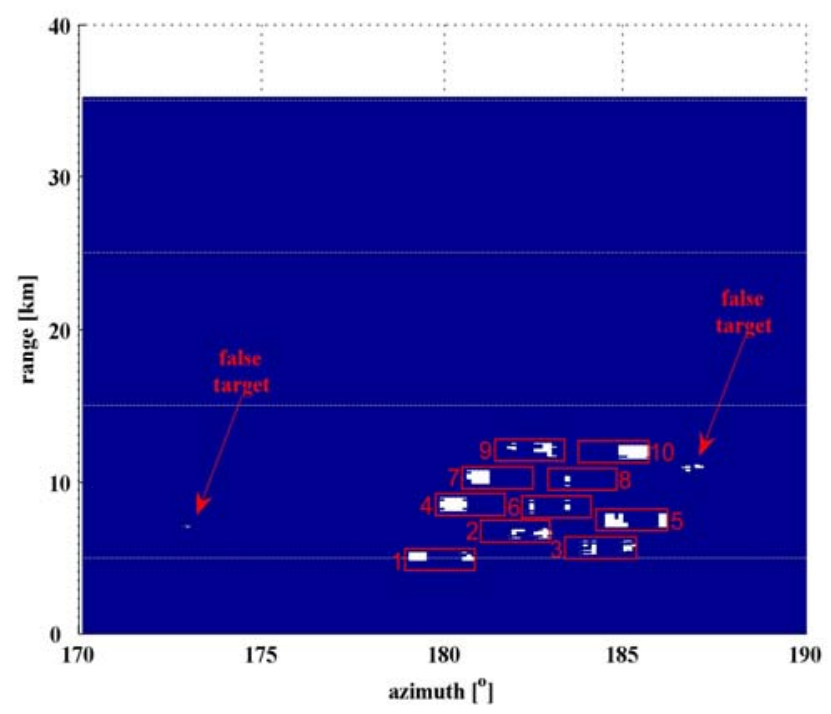

Figure 24. Result of LF-CFAR processing

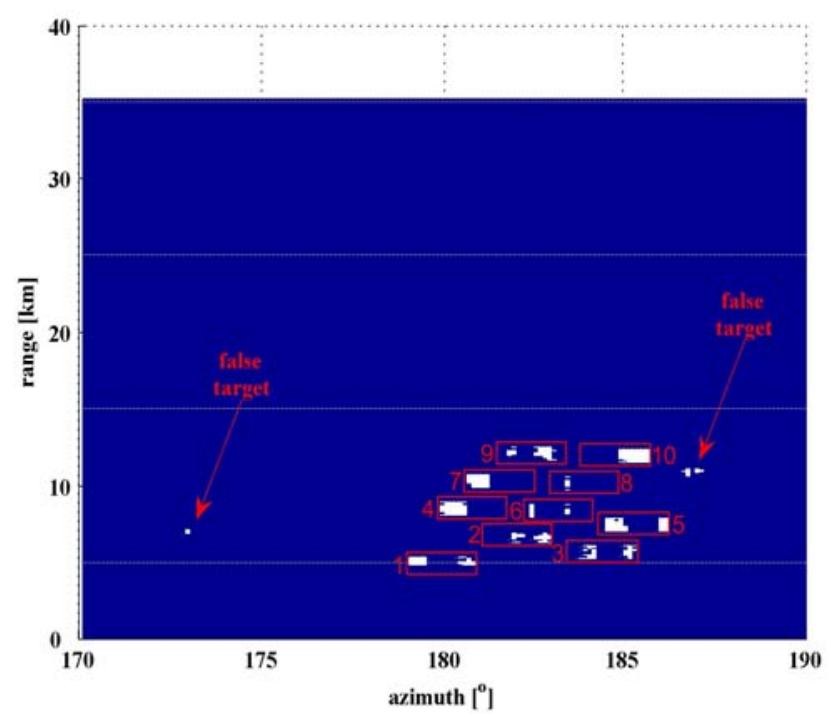

Figure 25. Result of NLF-CFAR processing 
We can see in Fig.21 that CA-CFAR detects all ten targets, but again there are a lot of false targets. TM-CFAR detects only targets 1, 4, 7 and 10 (see Fig.22), but there are no false targets. OS-CFAR does not detect only targets 6 and 8, but detections of the targets 2, 3 and 5 are very poor. Also, there are no false targets (see Fig.23). LF and NLF-CFAR detects all ten targets (see Fig. 24 and Fig.25) but two very weak false targets appear in the observed azimuth sector.

\section{Conclusion}

Fusion CFAR detectors give excellent results in terms of probability of detection, values of average decision threshold $[1,2,8]$ and in detection of very close multiple targets, as shown in this paper. Fusion of particular decisions of the internal CA, OS and TM-CFAR algorithms within fusion CFAR detectors provides better final decision and detection for multiple target situations. The advantage of using the fusion CFAR detector is shown in the situation of detection of simulated targets in a real clutter. All analyzed models of CFAR detectors in the article are supported using MATLAB ${ }^{\circledR}$ software.

Direction of further research would be moving toward an examination of characteristics of the realized fusion CFAR detectors under the conditions of jamming signal presence and its effect on detection of radar targets.

\section{References}

[1] IVKOVIĆ, D., ZRNIĆ,B., ANDRIĆ,M.: Fusion CFAR detector in receiver of the software defined radar, Proc. of the International Radar Symposium IRS-2013, 19.-21. June 2013, Dresden, Germany.

[2] IVKOVIĆ, D., ANDRIĆ,M., ZRNIĆ,B.: Nonlinear fusion CFAR detector, International Radar Symposium IRS-2015, 24.-26. June 2015, Dresden, Germany, DOI: 10.1109/IRS.2015.7226305, pp.481-486.

[3] FINN,H.M., JOHNSON,R.S.: Adaptive detection mode with threshold control as a function of spatially sampled clutter level estimate, RCA Rev., 1968, 29, (3), pp.414-464.

[4] ROHLING,H.: Radar CFAR thresholding in clutter and multiple target situations, IEEE Trans. Aerosp. Electron. Syst, 1983, 19, pp. 608-621.

[5] GANDHI,.P.P., KASSAM,S.A.: Analysis of CFAR processors in nonhomogenous background, IEEE Trans. Aerosp. Electron. Syst, 1988, 24, (4), pp.427-445.

[6] IVKOVIĆ,D., SIMIĆ,S., . DUKIĆ,M., ERIĆ,M.: Design and Implementation of Software Defined Receiver in a Conventional Radar, Proc. of the International Radar Symposium IRS-2005, Berlin, Germany, 2005.

[7] ESTRADA,S.L., CUMPLIDO,R.: Fusion center with neural network for target detection in background clutter, Proc. of the Sixth Mexican International Conference on Computer Science (ENC'05), 2005.

[8] IVKOVIĆ.D., ANDRIĆ.M., ZRNIĆ.B., OKILJEVIĆ.P., KOZIĆ.N.: CATM-CFAR Detector in Receiver of the Software Defined Radar, Scientific Technical Review, ISSN 1820-0206, 2014, Vol.64, No.4, pp. $27-38$

[9] PAPOULIS.A.: Probability, Random Variables and Stochastic Processes, McGraw-Hill, New York, USA, 1984.

\title{
Detekcija vrlo bliskih ciljeva pomoću fuzionih CFAR detektora
}

\begin{abstract}
U ovom radu su prikazani novi rezultati primene linearnog i nelinearnog fuzionog CFAR detektora. Razmatrana je detekcija vrlo bliskih ciljeva po azimutu i daljini. Cela simulacija je urađena na bazi softverski definisanog radarskog prijemnika. Svi realizovani modeli CFAR detektora su implementirani u pomenuti model radarskog prijemnika. $U$ radu je sprovedena komparativna analiza između fuzionih i pojedinačnih CA, TM i OS-CFAR detektora po pitanju detekcije vrlo bliskih ciljeva. Ciljevi su simulirani u realnom klateru.
\end{abstract}

Ključne reči: detektor, detekcija, akvizicija cilja, radar, softverski definisani radar, klater.

\section{Обнаружение очень близких целей с использованием гибридного детектора CFAR}

\begin{abstract}
В данной статье представлены новые результаты применения линейных и нелинейных слитых детекторов CFAR. Рассматривано обнаружение очень близких целей и по азимуту и по дальности. Весь процесс моделирования осуществляется на основе радиолокационного приёмника определяемого программным обеспечением. Все реализованные модели детектора CFAR реализованы в упомянутой модели приёмника радиолокационной станции. В работе проведён сравнительный анализ между слиянием и индивидуальными CA, TM и детектором OS-CFAR с точки зрения обнаружения очень близких целей. Цели моделируются в режиме реального времени местных помех.
\end{abstract}

Ключевые слова: детектор, обнаружение, целеуказание, радиолокационная станция, радиолокационная станция определена программным обеспечением, местные помехи.

\section{Détection des cibles très proches au moyen des détecteurs CFAR fusionnés}

\begin{abstract}
Les nouveaux résultats concernant l'application de détecteur linéaire et non linéaire CFAR fusionnés sont présentés dans ce papier. On a considéré la détection des cibles très proches par l'azimut et par la portée. La simulation entière a été faite à la base du récepteur radar défini par logiciel. Tous les modèles réalisés du détecteur CFAR ont été intégrés dans le modèle cité du récepteur radar. Dans ce travail on a effectué aussi l'analyse comparée entre les détecteurs CA, TM et OS -CFAR fusionnées et singuliers par rapport à la détection des cibles très proches. Les cibles ont été simulées dans le désordre réel.
\end{abstract}

Mots clés: détecteur, détection, acquisition de cible, radar, radar défini par logiciel, désordre. 